\title{
OS RISCOS PSICOSSOCIAIS RELACIONADOS COM O TRABALHO: IMPACTOS NA SUBJETIVIDADE DO TRABALHADOR
}

\author{
ARTIGO ORIGINAL \\ COELHO, Tatiani Moreira ${ }^{1}$ \\ SCATOLIN, Henrique Guilherme ${ }^{2}$
}

COELHO, Tatiani Moreira. SCATOLIN, Henrique Guilherme. Os riscos psicossociais relacionados com o trabalho: Impactos na subjetividade do trabalhador. Revista Científica Multidisciplinar Núcleo do Conhecimento. Ano 05, Ed. 03, Vol. 09, pp. 122-138. Março de 2020. ISSN: 2448-0959, Link de acesso: https://www.nucleodoconhecimento.com.br/psicologia/riscos-psicossociais

\section{RESUMO}

Várias foram as transformações que ocorreram no âmbito do trabalho no decorrer da história da civilização. Atualmente estamos diante da quarta revolução industrial que traz consigo novas formas de gestão do trabalho através da automatização dos processos produtivos. A presente pesquisa traz como objeto de estudo a subjetividade do trabalhador inserido no contexto industrial e tem como objetivo busca compreender como esses aspectos psicossociais influenciam na subjetividade desse trabalhador. Para abordar tais questões, esta pesquisa fará uso da revisão bibliográfica, tomando como pressuposto teórico a Psicodinâmica do Trabalho que compreende as dinâmicas que estão inseridas no contexto do trabalho, favorecendo uma análise crítica da organização do trabalho, esta causadora de todo sofrimento ocasionado pelas transformações advindas da modernidade. Através da pesquisa é possível

1 Graduação em Psicologia pela Fundação Herminio Ometto; pós graduada em Psicologia Organizacional e do Trabalho pela mesma instituição.

2 Doutor em Psicologia. 
compreender que a organização do trabalho pode favorecer o adoecimento e sofrimento mental dos trabalhadores que estão inseridos no contexto laboral.

Palavras-chave: Riscos psicossociais no trabalho, psicodinâmica do trabalho, saúde mental no trabalho, Mentalidade Enxuta.

\section{INTRODUÇÃO}

O mundo do trabalho tem sofrido diversas modificações ao longo da história. O trabalho artesanal passa a dar lugar às máquinas a vapor que foi símbolo da primeira revolução industrial. Foi acompanhado o surgimento das linhas de produção, com trabalhos fracionados e ritmos de produção determinadas por esteiras que foram a novidade da segunda revolução industrial, colocando em evidência o modelo de produção denominado Taylorista/Fordista (ANDRADE, 2017).

Este modelo de produção fracionada, na qual cada trabalhador é responsável por uma determinada tarefa, impacta diretamente na relação interpessoal entre os trabalhadores, pois contribui para a individualização dos sujeitos, reduzindo também o sentimento de cooperação entre eles (DEJOURS, 2015).

Com a terceira revolução industrial houve o surgimento da tecnologia e sistemas de informação incorporada às grandes organizações e com ela novos modelos de produção começaram a ganhar força, como por exemplo, o conceito de mentalidade enxuta ou Lean production através do Sistema Toyota de produção. Este foi disseminado mundialmente na década de 90, trazendo a ideia de lucro através da competitividade das organizações capitalistas com metas de controle de produção; eliminação de desperdício e custos, tendo seus fundamentos definidos por formas e trabalho mais flexíveis, gestão do trabalho e gestão da produção (STENGER et al, 2014).

Por fim, estamos vivenciando o acontecimento denominado Indústria 4.0, que faz referência a quarta revolução industrial e que traz consigo a ideia de automação dos 
processos produtivos, contribuindo na substituição de mão de obra humana por sistemas automatizados e robôs (TESSARINI JUNIOR et al, 2017).

Neste cenário, os trabalhadores que conseguem sobreviver as demissões acabam sendo expostos a trabalhos cada vez mais preconizados e, em alguns casos, desumanos. A demissão, que outrora era temida pelos trabalhadores, passou a ser realidade frequente nos diferentes níveis hierárquicos da organização. A instabilidade e insegurança no posto de trabalho, no emprego e na função que o trabalhador desempenha, acaba se consolidando como outro fator psicossocial: a ameaça a saúde coletiva. (STENGER et al, 2014)

Todas as mutações que acontecem no âmbito do trabalho acabam trazendo consigo muitos agravos a saúde física e mental dos trabalhadores e esses agravos são ocasionados pelos riscos psicossociais relacionados ao trabalho. Entende-se como riscos psicossociais relacionados ao trabalho a organização do trabalho, como por exemplo, a divisão do trabalho; o conteúdo das tarefas; a hierarquia e responsabilidade (DEJOURS, 1992; MENDES, 1995).

Entende se por condições de trabalho as pressões físicas, mecânica, química e biológica oriundos do posto de Trabalho. Essas pressões, ligadas às condições de trabalho, têm por alvo principal o corpo dos trabalhadores, ocasionando desgastes, envelhecimento e doenças somáticas (DEJOURS, 1994)

Assim, para compreender se os riscos psicossociais oriundos do trabalho geram impactos na subjetividade do trabalhador, este artigo fará uso de revisão bibliográfica para a discussão da problemática apresentada e utilizará como norteamento de pesquisa a abordagem da Psicodinâmica do Trabalho, uma vez que esta tem como foco de ação o próprio trabalho, compreendendo uma intervenção direcionada à organização do trabalho, uma vez que este é o fator fundamental para o sofrimento físico e mental dos trabalhadores (MENDES, 2007). 


\section{METODOLOGIA}

A fim de compreender os aspectos psicossociais que estão inseridos no contexto do trabalho e se eles ocasionam impactos na subjetividade do trabalhador; a presente pesquisa fez uso de uma revisão bibliográfica. De acordo com Del-Masso (2012), esta:

consiste em um texto breve, contendo as principais contribuições sobre o tema de estudo publicadas em revistas indexadas e livros de referência da área, demonstrando que o estudo é inovador, relevante e trará novidades para a temática escolhida (2012, p. 27).

Utilizamos como delineamento de pesquisa o enfoque qualitativo, pois ele "se preocupa, nas ciências sociais, com um nível de realidade que não pode ser quantificado"(MINAYO, 2002, p.21).

Para compor este artigo, buscou-se na base de dados do Scielo e Lilacs artigos científicos que fazem referências aos seguintes descritores: riscos psicossociais no trabalho, psicodinâmica, saúde mental no trabalho e mentalidade enxuta. Para tal, foi tomado como critério de inclusão artigos publicados no período de 2013 a 2018. Tomou como critérios de exclusão artigos publicados antes do período de 2013 e em idioma que não fosse o português. Somando-se todas as bases de dados e levando em consideração os critérios de inclusão e exclusão, foram encontrados 301 artigos. Após a leitura dos resumos, foram excluídos aqueles que não fazia referência ao contexto do trabalho e que não abordassem, em sua pesquisa, os impactos ocasionados pelo trabalho na saúde do sujeito, totalizando no final 17 artigos que contribuíram na elaboração da pesquisa. Realizou-se também uma busca manual em livros, utilizando os descritores de saúde mental e trabalho; psicodinâmica e subjetividade e foram encontrados, no total, 6 livros. Para tal, não houve filtro em relação ao ano de publicação. 


\section{FUNDAMENTAÇÃO TEÓRICA}

Observamos que foram grandes e significativas as modificações que ocorreram no âmbito do trabalho no decorrer da história da civilização. Evoluímos do trabalho artesanal para um trabalho que contempla sistemas automatizados de produção e passamos a inserir nas linhas de produção, das grandes organizações industriais, a figura do robô colaborativo que, diferente do ser humano, não adoece. A cada novo processo produtivo foi possível observar a criação de novas formas e compreensão do trabalho. As inovações tecnológicas modificaram a estrutura produtiva de países capitalistas e as relações de trabalho sofreram mutações, assim como metas e os objetivos destes. A forma de se fazer e enxergar o trabalho foram alterados para atender às novas exigências de mercado e social. (WATANABE, 2015).

Através dessas novas formas produtivas, elimina-se do trabalhador o controle e autonomia que o mesmo outrora tinha sobre seu trabalho e passa esse controle para as esteiras de produção que define não somente o ritmo que o trabalho deverá ser executado, mas também a sua forma e sequência. "O ambiente corporativo é pautado hoje por uma lógica capitalista globalizada, em que o aumento de produtividade e o lucro máximo são os objetos principais" (BRASIL, 2017, p.5).

Sobre o taylorismo, sistema produtivo que emergiu na Segunda Revolução Industrial; o autor Facas (2013) afirma que o trabalho se dá através de

tarefas prescritas, padronização de métodos, ferramentas e tarefas, com uma divisão social e hierárquica do trabalho que utiliza muitos supervisores, de modo a garantir supervisão a cada trabalhador, separadamente, tendo como suporte o controle, a punição e as regras (2013, p.33)

Nesse contexto, compreendemos que os trabalhadores, que estão inseridos dentro das organizações, em processos produtivos, principalmente aqueles que estão frente às esteiras de produção industrial, acabam sendo "[...]meros executantes das tarefas 
previamente planejadas [...] cujo cumprimento deve ser assegurado rigorosamente, a um ritmo que the é imposto [...] (DIAS, 2016, p.79-80).

Segundo a autora Watanabe (2015), as estruturas produtivas nos países capitalistas estão sendo alteradas devido às inovações tecnológicas que bebem da metodologia de Mentalidade Enxuta preconizada pelo Sistema Toyota de Produção, que ocorreu com a terceira Revolução Industrial. O conceito de mentalidade enxuta está atrelado a redução de custos através de desperdícios encontrados no processo produtivo, gerando, cada vez mais, o aumento de produtividade (STENGER et al, 2014).

O aumento da produtividade, atrelado aos avanços tecnológicos, têm custos. Ela se dá, muitas vezes, através da redução de mão de obra. Nesse contexto industrial, não há necessidade de grandes quantidades de pessoas para executar uma determinada tarefa, contribuindo para a redução no quadro de trabalhadores. O trabalhador que sobrevive as demissões deverá produzir em dobro e serão cobrados cada vez mais de se qualificarem para se manterem ativo nas organizações. (NETO, 2015).

As questões ligadas ao ambiente de trabalho, à organização, a caracterização e condição de trabalho, às oportunidades de desenvolvimento que este permite, ao balanço entre trabalho e vida fora dele, ao envelhecimento da população ativa e a precarização e insegurança no emprego, são, hoje em dia, considerados fontes de riscos psicossociais (COSTA \& SANTOS, 2013, p. 42).

Em meio a esse contexto de mudanças nos processos produtivos, os aspectos psicossociais vêm ganhando notoriedade diante dos questionamentos atuais no que se refere ao alto índice de trabalhadores acometidos por distúrbios osteomusculares e transtornos mentais ocasionados pelo trabalho.

Através dos dados do primeiro boletim quadrimestral sobre benefícios por incapacidade de 2017, disponibilizado pelo Ministério do Trabalho e da Previdência Social, podemos observar que os Transtornos Mentais e de comportamento são a 
terceira causa de incapacidade laboral nos períodos de 2012 a 2016, compreendendo, dentro destas, as que podem repercutir drasticamente na vida do trabalhador.

Esta evolução, apontada como uma das causas mais prováveis no que se refere ao absenteísmo laboral, está relacionada a problemas de saúde, como alterações músculo- esqueléticas ou doença cardiovasculares, esgotamentos profissionais ou transtornos de saúde mental. (RAMALHO \& COSTA, 2017 apud COELHO, 2009, p. 41)

Ainda segundo os autores citados acima, os aspectos psicossociais (como a pressão por ritmo de trabalho, jornada de trabalho em turnos, horas extras, sobrecarga física e mental) expõem o trabalhador a situações desgastantes.

Embora muito se fale sobre o assunto, ao abordar sobre o tema dos riscos psicossociais, devemos ter certa cautela, pois é possível observar equívocos com relação à utilização do termo. "É comum encontrarmos o termo associado a stress laboral [...]" (DIAS, 2016, p. 36)

De acordo com Dias (2016), o que denomina algo como risco psicossocial não se refere ao que este ocasiona na saúde do trabalhador (físico, social e mental) e sim aos fatores que estão ligados à origem desses riscos, como por exemplo, as condições de trabalho que os trabalhadores estão expostos, a organização e a gestão do trabalho.

A fim de compreender a questão abordada na pesquisa referente aos impactos na subjetividade do trabalhador ocasionados pelos riscos psicossociais do trabalho, faz necessário compreendermos as relações que se estabelecem no ambiente de trabalho. Para tal, discutiremos esse assunto, nos próximos tópicos, tomando como pressuposto teórico a Psicodinâmica do Trabalho.

\section{RESULTADOS E DISCUSSÕES}

Compreende se que o assunto referente aos riscos psicossociais relacionado ao trabalho tem tomado bastante notoriedade no mundo acadêmico. É possível 
considerar que há uma grande parcela de autores dedicados a discussão deste tema, mas poucos relacionam as consequências dos impactos destes riscos na subjetividade do trabalhador com as transformações que ocorreram no mundo do trabalho, através das grandes Revoluções Industriais, como agravantes do sofrimento e adoecimento dos sujeitos inseridos no contexto do trabalho. Sabe-se também que os impactos ocasionados pelos riscos psicossociais oriundos do ambiente laboral ocorrem, segundo Dejours (2015), diretamente no aparelho psíquico do trabalhador. O mesmo autor conclui que "o trabalho torna se perigoso para o aparelho psíquico quando ele se opõe à sua livre atividade" (DEJOURS, 1994, p. 24). Diante dos impactos ocasionados diretamente no aparelho psíquico do trabalhador, torna se importante o questionamento e aprofundamento nesse tema específico.

O contexto do trabalho sofreu inúmeras transformações e evoluiu da organização tradicional/ artesanal (que se moldava através de tarefas manuais) para tarefas em linhas automatizadas para atender as exigências do mercado atual que requer que as organizações sejam dinâmicas e flexíveis às mudanças necessárias para manterem se competitivas. (COSTA \& SANTOS, 2013). Compreende-se, através das ideias do autor supracitado, que da mesma forma que o mercado atual capitalista cobra para que as organizações sejam flexíveis e dinâmicas, busca-se a mesma postura do trabalhador, que ele venha se atualizar e se moldar de acordo com as exigências das novas formas de gestão afim de contribuir com a competitividade. "As transformações na natureza do trabalho e nas qualificações requeridas dos trabalhadores impostas pela Indústria 4.0 estão engendradas nesse pensamento" (TESSARI JUNIOR et al,2017, p. 9).

As transformações ocorridas (e que vem ocorrendo no contexto do trabalho) também é assunto bastante discutido entre os acadêmicos de engenharia Industrial que veem na Indústria 4.0 uma transformação bastante significativa e até diferente das ocasionadas nas outras três revoluções Industriais. Os autores Tessari Junior et al (2017) afirmam que, mesmo considerando as possibilidades de que o novo sistema de produção crie ou favoreça o aumento no número de postos de trabalho voltados às áreas de sistema de informação e engenharia de produção e produtos, há certa 
preocupação com os postos existentes na área produtiva através da substituição dos trabalhadores operacionais pelos maquinários e robôs colaborativos. Compreende-se que a substituição de trabalhadores por máquinas e robôs colaborativos contribuem para o que é denominado como desemprego estrutural.

Sobre o desemprego estrutural, Silva \& Pacheco (2017) afirmam que o mesmo pode ser compreendido como resultado das alterações econômicas e empresariais que tem por objetivo a automatização dos processos produtivo e "[...] caracteriza-se pelo seu caráter universal, atingindo todas as esferas da produção e dos serviços e expulsando massas de trabalhadores do processo produtivo" (LIMA, 2017, p .4). Compreende-se, através dos apontamentos dos autores, que várias áreas do setor organizacional podem ser afetados pela introdução da tecnologia e modificações da gestão do trabalho, porém a maior área impactada é o setor produtivo, setor este que geralmente encontra-se o maior número de trabalhadores dentro de uma organização.

Nesse contexto de transformações e na ânsia de atender às novas exigências que o trabalho Ihe impõe, o trabalhador passa a adoecer como é mostrado nos dados do Ministério do Trabalho e da Previdência Social ( pontuados na fundamentação teórica desta pesquisa), na qual expõe que os afastamentos do ambiente laboral (devido aos transtornos mentais com nexo causal com o trabalho e ocasionados pelos riscos psicossociais do mesmo) já se formulam como terceira causa de afastamento do mundo do trabalho (BRASIL, 2017).

Com esses dados é possível compreender que o adoecimento/sofrimento vivenciado e reportado pelos trabalhadores na atualidade possui relação com riscos psicossociais e está diretamente associado com os novos modelos de Gestão Industrial ocasionadas pelas grandes revoluções ocorridas no âmbito do trabalho (BORTELA \& MERLO, 2017; FACAS, 2013).

Sobre a mesma temática, Baruki (2015) expõe que: 
No ambiente ocupacional, diferentes tipos de riscos coexistem e com maior frequência do que em qualquer outro lugar. Sendo o ambiente de trabalho um espaço que, por excelência, integra a vida humana mais do que o próprio lar, é manifesto o papel que desempenha enquanto hospedeiro de agentes etiológicos que concorrem, de forma isolada ou combinada, para causar os mais diversos danos à saúde do trabalhador. (p.32)

Podemos compreender, através da exposição do autor supracitado, que as consequências e impactos que os riscos psicossociais ocasionam são diversas e para falar sobre estes, a autora Maia (2016) separa -os em 3 categorias: física, psicológica e mental. Na ordem do fisiológico se destaca os transtornos musculoesquelético, os transtornos cardiovasculares e digestivos; na ordem do psicológico pode-se destacar os problemas psicológicos, memória, depressão, dependência química, violência, doenças psicossomáticas (dentre outras) e. na ordem do mental. a depressão, esquizofrenia e paranoia (MAIA, 2016).

Sobre os efeitos negativos intrínsecos ao ambiente laboral pode se destacar os "aspectos do posto de trabalho e de seu entorno, tais como: o clima ou cultura organizacional, as funções, as relações interpessoais no trabalho e o desenho e conteúdo das tarefas" (WATANABE, 2015, p. 28).

A autora supracitada acima aponta que as pressões que o trabalhador recebe dos gestores podem entrar em confronto com suas próprias necessidades, desejos e os valores que possui e, através disso, despertar vivências e comportamentos de insegurança; sentimento de tristeza, de raiva, medo e vergonha, que se não prevenidos ou controlados podem evoluir para um intenso sofrimento psíquico. Ainda segundo a autora, "caso estas situações opressivas e desgastantes se tornem contínuas e não existam condições para seu enfrentamento, o processo de desgaste assume um caráter mórbido" (WATANABE, 2015, p. 36).

O caráter mórbido assumido como efeito dos riscos psicossociais também é pontuado pela autora Maia (2016), na qual também compreende que os impactos ocasionados 
pelos riscos psicossociais são fatores contributivos para o adoecimento, para o sofrimento do trabalhador, podendo ocasionar tanta dor que se não tratada, não prevenida, pode contribuir para que o sujeito chegue ao limite de sua existência e cometa o suicídio. (MAIA, 2016).

Diante disso, compreende-se que o trabalho, quando realizado sob condições de pressão por metas de produção e de qualidade, é considerado como um trabalho estressante, o que pode contribuir com os esgotamentos físicos e psíquicos dos trabalhadores inseridos neste contexto (STENGER et al, 2014; WATANABE, 2015).

Vários autores concordam na opinião de que os riscos psicossociais englobam as percepções e as experiências do trabalhador, assim como a organização do trabalho; às influências sociais e econômicas, a cultura organizacional; as relações interpessoais; tais como o conteúdo da tarefa e as condições de trabalho. Se não prevenidos acabam gerando impactos negativos tanto para os trabalhadores quanto para as organizações industriais. Para os trabalhadores, os impactos encontrados se dão na ordem da saúde física (LER/DORT) e mental (estresse e desgaste emocional) e estão diretamente relacionados aos acidentes de trabalho. Para a organização, os impactos ocorrem no âmbito do financeiro, na qualidade da produção e trabalho através de custos relacionados a saúde, turnover e absenteísmo (WATANABE, 2015; STENGER et al, 2014; MACEDO et al, 2016; DIAS, 2016; FACAS, 2013).

Segundo Dejours (2015), a organização do trabalho entra em confronto com a vida mental do trabalhador, causando impacto na esfera das aspirações do sujeito, das motivações e dos seus desejos. O autor ainda afirma que as condições de trabalho têm um alvo específico que é o corpo do trabalhador; a organização do trabalho, por sua vez, atuará no funcionamento do aparelho psíquico do sujeito. De acordo com o autor supracitado, o fracionamento das tarefas e os modos operatórios instiga o sentimento e o interesse do trabalho para o trabalhador, enquanto a divisão dos homens busca, acima de tudo, as interrelações entre os sujeitos, incitando os investimentos afetivos existentes através destes, como o amor, o ódio, as amizades, a solidariedade, a parceria, a confiança, dentre outros (1994, p. 126). 
Nas indústrias podemos considerar que os risco psicossociais, como as relações hierárquicas com a chefia e com outros trabalhadores, assim como os ritmos impostos de trabalho, o salário, os prêmios (através de competições internas) são, muitas vezes, desagradáveis e até insuportáveis para o trabalhador, aparecendo como fonte geradora de ansiedades; pois pode contribuir para um sentimento de incapacidade e preocupação em não conseguir acompanhar o ritmo de produção, não atendendo as expectativas da organização (DEJOURS, 2015) .

Martins (s/d) compreende o trabalho como uma atividade humana, podendo ser realizada de modo individual e/ou coletivo e que os trabalhadores, inseridos no ambiente organizacional, precisam contribuir com seus esforços, com seu tempo, com suas habilidades e com suas competências para executá-lo. Entretanto, o trabalhador, ao realizar as atividades, espera receber em troca de seu trabalho, retribuições econômicas, materiais, psicológicas e sociais, que satisfaçam as suas necessidades e desejos.

Quando o trabalho não leva em consideração a subjetividade e os desejos do trabalhador, quando não permite a adaptação da organização, não fornecendo espaço para controle e autonomia nas transformações da organização, o sofrimento patológico fica em evidências (RANCAN \& GIONGO, 2016; FACAS, 2013). Esse sofrimento, de acordo com Dejours (2015), é originado do choque entre a história de vida do trabalhador versus organização do trabalho, pois há bloqueio entre a relação do homem e seu trabalho, pois a organização do trabalho acaba não levando em consideração os desejos do sujeito.

Ainda segundo o autor supracitado, no trabalho existe a possibilidade de diminuição da carga psíquica. Se isso ocorrer, este trabalho passa a ser considerado como um trabalho equilibrado. Se, por sua vez, não haja essa possibilidade, o trabalho continua a ser considerado fatigante/estressante (DEJOURS, 2015).

Mesmo diante de todas essas ponderações, que faz referência ao trabalho como causador de todos os sofrimentos e agravos a saúde física e mental do trabalhador na atualidade, alguns autores expõem que esse mesmo trabalho pode ser fonte de 
realização e criatividade. Sobre isso, Dejours (1994) aponta que "[...] entre as pressões do trabalho e a doença mental interpõe se um indivíduo, não somente capaz de compreender sua situação, mas capaz também de reagir e se defender" (p. 123).

Embora seja possível compreender a organização do trabalho e o próprio trabalho como fonte de sofrimento e de adoecimento, também é possível compreendê-lo como fator contributivo para a saúde mental de trabalhadores e trabalhadoras, pois possibilita que mesmos desenvolvam estratégias de enfrentamento que possibilitam lidar com o sofrimento ocasionado por este (FACAS, 2013; BORTEGA \& MERLO, 2017). Entretanto, é necessário considerar sempre os impactos advindos da organização, impactos estes que podem gerar prazer, sofrimento e adoecimento (BORTEGA \& MERLO, 2017).

Segundo Facas (2013), o trabalho nem sempre ocupa um lugar de sofrimento, mas sim da "possibilidade de construção de uma identidade e de expressão da subjetividade (p.22). Sobre isso, Clot. (2006) define o trabalho como uma capacidade para estabelecer engajamentos aos trabalhadores; além disso, ele afirma que o mesmo ocupa papel central na vida do sujeito, pois "a própria identidade do sujeito é resultado de uma conquista que passa por um reconhecimento do 'trabalhador' no Homem". (p 59)

Sobre isso, aponta que:

No trabalho artesanal que precedia a organização científica do trabalho e, ainda hoje, rege as tarefas muito qualificadas, uma parte da organização do trabalho provêm do próprio operador. A organização temporal do trabalho, a escolha das técnicas operatórias, os instrumentos e os materiais empregados permitem ao trabalhador, dentro de certos limites é claro, adaptar o trabalho às suas aspirações e às suas competências" (DEJOURS, 1994, p. 52). 
Compreende-se que, quando o trabalhador tem possibilidades de transformação da organização, quando há controle e autonomia do trabalho, quando o trabalhador é reconhecido por aquilo que faz. temos então saúde (FACAS, 2013).

Para auxiliar na compreensão das dinâmicas que estão inseridas no contexto laboral e como compreendê-las, das estratégias que os trabalhos utilizam para lidar com os agravos advindos do contexto laboral em que o mesmo está inserido, faz necessária a compreensão do trabalho à luz da psicodinâmica do trabalho que, de acordo com Watanabe (2015), é utilizado como referência, os conceitos da ergonomia, do trabalho prescrito $x$ trabalho real, levando sempre em consideração os aspectos relacionados à organização do trabalho tais como o ritmo de produção, jornada, relações interpessoais e hierárquicas, responsabilidades, tomada de decisão e controle.

Dejours (1994) denomina o estudo das dinâmicas existentes e inseridas no contexto do trabalho como psicopatologia do trabalho. Segundo o autor, ela é:

A análise dinâmica dos processos psíquicos mobilizados pela confrontação do sujeito com a realidade do trabalho." Dinâmico" significa que a investigação toma como centro da gravidade os conflitos que surgem do encontro entre o sujeito, portador de uma história singular, preexistente a este encontro e uma situação de trabalho cujas características são, em grande parte, fixadas independentemente da vontade do sujeito. Isto implica que, em psicopatologia do trabalho, partimos de uma subjetividade já constituída, que vai, em um tempo geneticamente ulterior, ser exposta à realidade do trabalho. Isto significa que o sujeito corre o risco de não ser mais o mesmo que antes do início do conflito e que a realidade do trabalho também corre o risco de ser transformada através do efeito de uma sublimação de subjetividade ( $p$. 120).

É possível compreender que mesmo diante das situações mais adversas do trabalho, os trabalhadores ali inseridos podem elaborar estratégias defensivas para lidar com esse contexto. Sobre estratégias defensivas, Dejours (1994) afirma que elas 
funcionam como troca de posição dos trabalhadores em relação ao seu trabalho, passando de vítimas passivas em relação ao trabalho, para agentes ativos. De acordo com o autor, essa troca de posição é "estritamente mental, já que ela não modifica a realidade da pressão patológica "(p. 128).

Ainda sobre isso, o autor expõe que o bem-estar psíquico vem através do conteúdo da tarefa que é desempenhado pelo trabalhador em seu ambiente de trabalho. Sobre isso, o mesmo autor informa que "em termos econômicos, o prazer do trabalhador resulta da descarga de energia psíquica que a tarefa autoriza, o que corresponde a uma diminuição da carga psíquica do trabalho" (DEJOURS, 1994, p. 24).

Frente as situações estressantes que 0 ambiente de trabalho proporciona, o trabalhador acaba utilizando de estratégias defensivas, com o objetivo de lidar e administrar as demandas internas e ambientais como angústia e insatisfação no trabalho, gerenciando os conflitos que vão surgindo neste contexto. (BORGES \& e ARGOLO , 2004; DEJOURS, 2015)

Mendes (2013) pontua que o próprio trabalhador não se defende do sofrimento, o que ele faz é desenvolver estratégias para enfrentá-los e lidar com eles em seu dia a dia laboral. Essas estratégias são chamadas de criativas e seu objetivo é a busca pelo prazer no trabalho, uma vez que possibilita o trabalhador utilizar a sua criatividade com a organização. No entanto, deve-se ficar atento, pois esse tipo de estratégia de enfrentamento pode favorecer o mascaramento do sofrimento, pois essas estratégias não facilitam a sua identificação (DEJOURS, 2015).

\section{CONCLUSÃO}

Essa pesquisa teve como objetivo compreender se os riscos psicossociais (oriundo do trabalho) ocasionam algum impacto na subjetividade do trabalhador inserido nas organizações industriais que mantêm, como modelo de Gestão Industrial, os sistemas de produção advindos das grandes Revoluções Industriais, como por exemplo, Trabalho em linhas de produção; o trabalho fracionado frente às esteiras de produção de Taylor e o Sistema Toyota de produção (com a ideia de Mentalidade Enxuta). 
Os resultados mostram que a organização do trabalho pautada nos modelos de gestão supracitados pode sim contribuir para o adoecimento e sofrimento do trabalhador imposto a esse sistema cada vez mais otimizado como a proposta de redução no quadro de trabalhadores, trabalho cada vez mais fracionado com ritmo controlado pelas esteiras; colocando em pauta um problema da ordem social: o desemprego.

Compreende-se que cada trabalhador lida de um a forma distinta quando colocado frente a situações estressantes e desgastantes. As estratégias de enfrentamento também são diversas; no entanto, fica claro que há necessidade de intervenção frente às questões oriundas do trabalho. A partir deste contexto, este artigo pode citar que os impactos são diversos na saúde física e mental e que o número de afastamentos têm aumento a cada ano que passa.

A partir destes apontamentos, seria interessante novos estudos com a abordagem voltada para esse tema, uma vez que há carências de estudos no que se refere a Saúde Mental dos trabalhadores que estão expostos a todos os riscos psicossociais intrínsecos nas organizações.

\section{REFERÊNCIAS}

ANDRADE.P.Z.A.M. A quarta revolução Industrial e sua relação com a produtividade atual: uma revisão de literatura. Brasilia.2017.Disponível em:< http://bdm.unb.br/bitstream/10483/17633/1/2017_PedroSimoesAntunesdeMouraAndr ade_tcc.pdf> Acesso em 24 de Maio de 2015.

BARUKI. L, V. Riscos Psicossociais e Saúde Mental do Trabalhador: por um regime Jurídico preventivo. São Paulo: LTr,2015.Disponível em:<http://www.ltr.com.br/loja/folheie/5047.pdf > Acesso em:02 de setembro de 2018.

BRASIL, Ministério do Trabalho e Previdência Social. Adoecimento Mental e Trabalho. A concessão de benefícios por incapacidade relacionados a transtornos mentais e comportamentais entre 2012 e 2016.Brasília: 1ำ boletim 
Quadrimestral sobre benefícios por incapacidade, 2017.Disponível em:< http://sa.previdencia.gov.br/site/2017/04/1\%C2\%BA-boletim-quadrimestral.pdf $>$ Acesso em 01 de setembro de 2018

BOTTEGA, C.G; MERLO, A.C. Clínica do trabalho no sus: possibilidade de escuta aos trabalhadores. Psicol. Soc., Belo Horizonte, v. 29, e156376, 2017. Disponível em:<http://www.scielo.br/scielo.php?script=sci_arttext\&pid=S0102-

$71822017000100222 \&$ Ing=en\&nrm=iso $>$. Acesso em:28/08/2018

COSTA, L. S; SANTOS, M. Fatores Psicossociais de risco no Trabalho: lições aprendidas e novos caminhos. Internacional Journal on Working Conditions, N.5.2013.Disponível em:< https://sigarra.up.pt/fpceup/pt/pub_geral.pub_view?pi_pub_base_id=88066>Acesso em 27 de agosto de 2018

CLOT,.Y. A função psicológica do trabalho. Petrópolis: Vozes,2006.

DEL-MASSO M.C.S. Metodologia do trabalho Científico. Disponível

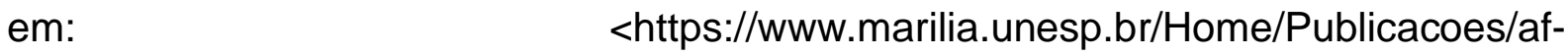
v6_colecao_delmasso_2012-pcg.pdf >Acesso em 24 de Maio de 2018.

DEJOURS, C.A loucura do trabalho: estudo de psicopatologia do trabalho. 6 ed.São Paulo, Oboré, 2015.156p.

DEJOURS, C. Psicodinâmica do Trabalho. Contribuições da Escola Dejouriana à análise da Relação Prazer, Sofrimento e Trabalho. São Paulo, Atlas, 1994.145p.

DIAS. J. B; A. A. (In) visibilidade dos Riscos Psicossociais: propostas de intervenção numa empresa da indústria de automóvel. (Dissertação de mestrado).Universidade do Porto.Porto.2016.Discponível em < https://repositórioaberto.up.pt/btstream/10216/88952/2/168706.pdf. Acesso em:23 de julho de 2018.

FACAS , E. P. Protocolo de avaliação de riscos psicossociais no trabalhoContribuições da Psicodinâmica do trabalho. Programa de Pós- Graduação em 
Psicologia Social, do Trabalho e das organizações, Instituto de Psicologia, Universidade de Brasília, Brasília, 2013. Brasil. Disponível em: < http://lpct.com.br/wpcontent/uploads/2012/11/1-2013_EmilioPeresFacas.pdf.> Acesso em: 27 de agosto de 2018.

\section{LIMA, J. S. O FENÔMENO DO DESEMPREGO ESTRUTURAL: sua particularidade} no rural brasileiro do século XXI .VIII Jornada Nacional Políticas Públicas.Universidade Federal do Maranhão.Centro de Ciências Humanas.Programa de pós graduação em políticas públicas.Disponível em http://www.joinpp.ufma.br/jornadas/joinpp2017/pdfs/eixo2/ofenomenododesemprego estruturalsuaparticularidadenoruralbrasileirodoseculoxxi.pdf.Acesso em:10 de setembro de 2018.

MACEDO, K. B; LIMA,J.G;FLEURY,A.R.D;CARNEIRO,C.M.S. Organização do trabalho e adoecimento: uma visão interdisciplinar. Goiânia: PUC Goiás,2016.332p.

MAIA, S. I. S. Relatório de atividade profissional. Suicídio (ou tentativa): acidente de trabalho ou doença de trabalho? Universidade de Minho. Escola de Direito.2016. Disponível em: < http://hdl.handle.net/1822/44558 > Acesso em 02 de setembro de 2018.

MARTINS, M. C. A. (s/d). Factores de risco psicossociais para a saúde mental. Disponível em:<http://www.ipv.pt/millenium/Millenium29/33pdf. Acesso em:28/08/2018

MENDES, A.B. Aspectos psicodinâmicos da relação homem-trabalho: as contribuições de C. Dejours. Psicol. cienc. prof. [online]. 1995, vol.15, n.1-3, pp.3438. ISSN 1414-9893.Disponível em: _<http://www.scielo.br/scielo.php?script=sci_arttext> Acesso em 09 de maio de 2018

MENDES. A.M. Psicodinâmica do Trabalho: teoria, método e pesquisa. São Paulo: Editora. Casa do Psicólogo,2007.360p. 
MINAYO, M. C.S.(Org.) Pesquisa Social: teoria, método e criatividade.21. Ed, Rio de Janeiro: Vozes, 2002.

NETO, H.V. Estratégias organizacionais de gestão e intervenção sobre riscos psicossociais do trabalho. International Journal on Working Conditions.N.9.2015. Disponível em: <http://ricot.com.pt/artigos/1/IJWC.9_HVN.p.1-21.pdf >.Acesso em 28 de agosto de 2018.

RAMALHO, J. \& COSTA, L. S. (2017). Os Fatores Psicossociais de Risco na Atividade de Técnicos Superiores de Segurança no Trabalho. Laboreal, 13(2), 3949. Disponível em: <http://laboreal.up.pt/files/articles/39_49.pdf>.Acesso em:27/08/2018

RANCAN, M. GIONGO, C. R., "Eles determinam, nós produzimos": subjetividades capturadas pelo trabalho metal mecânico". Psicologia \& Sociedade, 28(1), 135-144. 2016.Disponível em: <http://dx.doi.org/10.1590/180703102015v28n1p135> Acesso em 28 de agosto de 2018

SILVA,T.J.A;PACHECO,T.P.As consequências psicossociais do desemprego.Revista Amazônida ILES/ULBRA Porto Velho, v. 1, n. 2 (2017) .Disponível

em:<http://www.periodicos.ulbra.br/index.php/amazonida/article/view/2997/2554>.Ac esso em 08 de setembro de 2018.

STENGER, E; MONTEIRO, M. I ; SABINO, M. O; MIQUILIN, I. O. C; CORRÊA FILHO,H. R. C. Lean production e riscos psicossociais: o caso de uma fusão multinacional de grupo metal mecânico no Brasil. Cad. Saúde Pública, Rio de Janeiro, v. 30, n. 8, p. 1765-1776, ago. 2014. Disponível em<http://www.scielo.br/pdf/csp/v30n8/0102-311X-csp-30-8-1765.pdf >. Acessos em 12 maio 2018.

TESSARI JUNIOR, G; SALTORATO, P: MORENO, M, G, M; OliveIRA, J, M. Indústria 4.0 e reestruturação produtiva: estratégias do capital e suas implicações para o trabalho .Congresso Brasileiro de Engenharia de Produção. 
Ponta

Grossa,

PR.Brasil.2017.Disponível

em:<http://www.aprepro.org.br/conbrepro/2017/down.php?id=3072 > Acesso em: 02 de setembro de 2018.

WATANABE.E.M.B. Aspectos psicossociais de risco no trabalho e a saúde mental dos carteiros da cidade de São Paulo.2015.Disponível em: $<$ http://www.fundacentro.gov.br/biblioteca/bibliotecadigital/acervodigital/detalhe/2016/1/aspectos-psicossociais-de-risco-no-trabalho-e-asaude-mental-dos-carteiros-da-cidade-de-sao>Acesso em: 09 de maio de 2018.

Enviado: Setembro, 2019.

Aprovado: Março, 2020. 